\title{
A memória da Covid-19 no Brasil em sites oficiais ${ }^{1}$
}

\author{
Ana Javes LUZ ${ }^{2}$
}

\begin{abstract}
Resumo:
O artigo apresenta a pesquisa documental realizada nos sites criados pelos 26 governos estaduais, pelo governo do Distrito Federal e pelo Ministério da Saúde para informar sobre a pandemia do novo coronavírus. Apresenta os tipos de informações ofertadas nessas mídias institucionais e trata da importância da preservação das páginas para garantir o direito à informação sobre a Covid-19 no Brasil. Teoricamente, aciona os conceitos de preservação digital, arquivamento da web, comunicação pública, comunicação governamental e memória. Metodologicamente, além da pesquisa documental, operacionalizada por meio de navegação orientada, utiliza o software Conifer para capturar as páginas iniciais de todos os sites analisados e disponibilizá-las publicamente. Conclui que a preservação dessas mídias é condição para garantir a memória sobre a pandemia no país, atendendo ao princípio da transparência pública esperada nas democracias.
\end{abstract}

Palavras-chave: Covid-19; preservação digital; comunicação pública; comunicação governamental; memória.

\section{The memory of Covid-19 in Brazil at official websites}

\begin{abstract}
:
This article presents the documentary research on the websites created by the 26 state governments, the Federal District government and the Health Ministry of Brazil to communicate about the new coronavirus. It exposes the information offered in these institutional media and discusses the importance of these websites preservation and their content to guarantee the right to information about Covid-19 in Brazil. It uses the concepts of digital preservation, web archiving, public communication, government communication and memory. Methodologically, in addition to documentary research, through guided navigation, it uses Conifer software to capture the home pages of all analyzed sites and make them publicly available. It concludes that the preservation of these media is a condition to guarantee the memory of the pandemic in the country, meeting the principle of public transparency expected in democracies.
\end{abstract}

Keywords: Covid-19; digital preservation; public communication; government communication; memory.

\section{La memoria de la Covid-19 en Brasil en sitios web oficiales}

\section{Resumen:}

El artículo presenta la investigación documental realizada en los sitios web creados por los 26 gobiernos estatales, el gobierno del Distrito Federal y el Ministerio de Salud de Brasil para informar sobre la pandemia del nuevo coronavirus. Presenta los tipos de información que se publican en estos medios institucionales y aborda la

\footnotetext{
${ }^{1}$ O presente trabalho foi realizado com apoio da Coordenação de Aperfeiçoamento de Pessoal de Nível Superior (CAPES) - Brasil - Código de Financiamento 001.

2 Jornalista. Doutoranda em Comunicação e Informação na Universidade Federal do Rio Grande do Sul (PPGCOM/UFRGS). Coordenadora Executiva do Observatório da Comunicação Pública (OBCOMP) e integrante da rede de pesquisa do Instituto Nacional de Ciência e Tecnologia em Democracia Digital (INCT.DD).

E-mail: anajaves@gmail.com
} 
importancia de preservar las páginas web para garantizar el derecho a la información sobre la Covid-19 en Brasil. Teóricamente, utiliza los conceptos de preservación digital, archivo web, comunicación pública, comunicación gubernamental y memoria. Metodológicamente, además de la investigación documental, operacionalizada a través de la navegación guiada, utiliza el software Conifer para capturar las páginas iniciales de todos los sitios analizados y ponerlos a disposición del público. Concluye que la preservación de estos medios es una condición para asegurar la memoria sobre la pandemia en el país, cumpliendo con el principio de transparencia pública esperado en las democracias.

Palabras clave: Covid-19; preservación digital; comunicación pública; comunicación gubernamental; memoria.

Tudo o que o homem podia ganhar no jogo da peste e da vida era o conhecimento e a memória. Albert Camus, A Peste (1947)

\section{Introdução}

A Covid-19, doença causada pelo novo coronavírus, pegou o mundo de surpresa. A doença, que teve sua primeira identificação em dezembro de 2019 na cidade de Wuhan, China, velozmente se espalhou por diversos países e obrigou as autoridades sanitárias a medidas de orientação, prevenção e pesquisa sobre o novo patógeno, a fim de prevenir contaminações e mortes. Em 30 de janeiro de 2020, a Organização Mundial da Saúde alertou que a doença constituía uma Emergência de Saúde Pública de Importância Internacional - o mais alto nível de alerta da Organização (WORLD HEALTH ORGANIZATION, 2020a) - e, em 11 de março de 2020, a Organização caracterizou a Covid-19 como uma pandemia (WORLD HEALTH ORGANIZATION, 2020b) - exigindo que governos de todo o mundo adotassem medidas urgentes para conter o avanço da doença em seus territórios.

Dentre as medidas preventivas, a oferta de informações confiáveis se mostrou uma necessidade imediata. Por se tratar de uma doença nova, orientações sobre modos de contágio, prevenção e cuidados se tornaram indispensáveis para a população, para os profissionais de saúde e para o trabalho da imprensa, cuja pauta, justificadamente dominada pelo tema, exigia também informações diárias sobre o avanço dos casos no país. Rapidamente, a comunicação institucional assumiu papel central nas estratégias governamentais.

Este artigo discute a importância de preservar os sites oficiais brasileiros criados durante a pandemia para informar sobre o novo coronavírus, compreendendo que o acervo disponível nesses canais institucionais de comunicação permite reconstituir a memória da doença no país. 
O conjunto de informações neles disponibilizados é a memória do enfrentamento da doença, da atuação governamental, bem como da comunicação oficial empreendida no período.

Teoricamente, são relacionados os conceitos de preservação digital, de arquivamento da web, de comunicação pública, comunicação governamental e memória a fim de embasar as análises realizadas. Empiricamente, o trabalho apresenta pesquisa documental de caráter qualitativo nos sites criados pelo Ministério da Saúde, pelos 26 governos estaduais e pelo governo do Distrito Federal sobre a doença. Ao final, traz considerações sobre como a transparência pública, a accountability, o direito à informação e à memória se relacionam com a preservação dessas mídias institucionais.

\section{Preservação digital, comunicação e memória}

Nunca se produziu e se fez circular tanta informação ao mesmo tempo em que nunca se perdeu tanta informação como nos dias atuais. A chamada Era da Informação, marcada pelo desenvolvimento e consolidação das Tecnologias da Informação e da Comunicação (TICs), facilitou a produção, a difusão, o processamento e o armazenamento de grande quantidade de dados, mas também permite seu descarte ou perda definitiva em alguns cliques (FORMENTON; GRACIOSO, 2020). É nesse cenário que discutir o direito à informação, especialmente quando se trata das informações produzidas pelo Estado, significa também discutir a preservação e o acesso à informação nascida digital, isto é, aquela que não existe em outro formato originalmente e, caso deletada, pode ser irrecuperável.

Pimenta e Canabarro (2014) afirmam que o desenvolvimento das TICs transformou, definitivamente, a maneira como governos lidam com os dados oficiais, com o processo de produção, o armazenamento, o acesso e a partilha de informações. Governos também estão entre os maiores comunicadores em todo o mundo. Para Howlett $(2009$, p. 23, tradução da autora), "comunicações governamentais são uma grande indústria em crescimento em muitos países e estão sujeitas a uma atenção crescente de profissionais e teóricos" ${ }^{3}$. São dados e informações disponibilizados, prioritariamente, em formato digital nos sites e plataformas oficiais.

\footnotetext{
${ }^{3}$ No original: "Government communications is now a large growth industry in many countries and the subject of increasing attention from both practitioners and theorists" (HOWLETT, 2009, p. 23).
} 
Ocorre que apenas $20 \%$ de um conjunto de endereços se mantêm válidos na internet após um ano (NTOULAS; CHO; OLSTON, 2004). Isso sem falar nos sites que, mesmo permanecendo válidos, têm seus conteúdos modificados, tornados inacessíveis ou excluídos. Por isso, como defendem FREY et al (2002), uma política informacional ativa por parte dos governos é essencial para uma prática transparente e responsável. É precondição para a sociedade civil exercer sua função de controle social.

A preservação digital e o arquivamento de websites se tornaram, assim, agenda acadêmica, política e administrativa em todo o mundo. Em 2003, a Organização das Nações Unidas para a Educação, a Ciência e a Cultura (Unesco) divulgou a "Carta sobre a Preservação do Patrimônio Digital”, na qual defende a importância de preservar recursos únicos nas áreas do conhecimento e da expressão humana, sejam eles de ordem "cultural, educativo, científico e administrativo ou que contenham informações técnicas, jurídicas, médicas ou de outros tipos"4 (UNESCO, 2003, não paginado, tradução da autora), criados digitalmente ou convertidos em formato digital, como forma de garantir o acesso desses conteúdos às gerações presente e futuras.

Também em 2003, foi criado na França o Consórcio Internacional para a Preservação da Internet (IIPC), entidade que reúne atualmente mais de 55 instituições entre bibliotecas públicas, arquivos nacionais, museus e instituições de patrimônio cultural com o objetivo de preservar os conteúdos disponíveis nos websites de instituições públicas e privadas em mais de 45 países - o Brasil excluso.

No Brasil, os estudos sobre arquivamento da web são promissores, mas as políticas públicas de preservação de sites oficiais e de suas informações, ainda são raras. De acordo com Rockembach (2018a) - que realizou levantamento de estudos sobre web archiving na base de dados Scopus, compreendendo um intervalo de 15 anos (2002 a 2016) - no período analisado não foram identificadas iniciativas de arquivamento da web em andamento no Brasil. E quando

\footnotetext{
${ }^{4}$ Texto completo no original: "El patrimonio digital consiste en recursos únicos que son fruto del saber o la expresión de los seres humanos. Comprende recursos de carácter cultural, educativo, científico o administrativo e información técnica, jurídica, médica y de otras clases, que se generan directamente en formato digital o se convierten a éste a partir de material analógico ya existente. Los productos "de origen digital" no existen en otro formato que el electrónico" (UNESCO, 2003, não paginado).
} 
observada a plataforma Internet Archive, considerada o maior arquivo da web do mundo, os sites brasileiros são encontrados de forma esparsa (ROCKEMBACH, 2018b).

Outro estudo, que diagnosticou a preservação da comunicação governamental nos sites das prefeituras de capitais brasileiras, demostrou que em 33\% das páginas pesquisadas já não era possível encontrar notícias, campanhas publicitárias, registros em vídeo, áudio ou foto de governos passados (LUZ; WEBER, 2018). O levantamento apontou ainda que, em capitais cujos sites preservaram conteúdos de governos anteriores, esse arquivamento foi parcial, não tendo sido possível identificar um padrão ou política de preservação específica para a comunicação governamental. A ausência de políticas de preservação de sites governamentais e de seus conteúdos compromete a memória, especialmente a memória política e a comunicacional.

A comunicação governamental é fonte de informação que importa para além do momento em que é veiculada, pois não se trata apenas de dar visibilidade às ações de um governo enquanto esse estiver em curso. Ela oferece as condições necessárias para que a sociedade esteja informada a respeito dos assuntos de interesse coletivo.

As variáveis da comunicação das democracias têm origem na informação e na participação, através de processos de visibilidade e acessibilidade que permitem saber, refletir, argumentar, se posicionar e deliberar. [...] Sem informação não há argumentação e sem possibilidade de criticar, argumentar, não há comunicação, sobressai a propaganda, a divulgação do poder que tenta se legitimar e, portanto, não há comunicação pública. (WEBER, 2017, p. 28, grifos no original).

Por isso, nas democracias, a comunicação governamental deve ser observada e tensionada a partir dos princípios que regem a Comunicação Pública. Isto é, abordar temas de interesse público, favorecer o debate público e a formação da opinião pública. A comunicação pública é indicadora de qualidade das democracias (WEBER, 2017).

Além de incidir sobre o debate público quando da sua consecução, a comunicação governamental é também fonte histórica, na medida em que o acesso aos seus acervos permite resgatar discursos, entrevistas, notícias e outras formas de registros que remontam a um governo, a uma sociedade e a dinâmicas socioculturais (LUZ, 2016). É possível, por exemplo, recuperar as razões que nortearam a adoção dessa ou daquela política pública. Permite, 
igualmente, observar como um governo se comportou em um momento de crise política ou institucional ou diante da morte de milhares de cidadãos em razão de uma nova doença. Se a comunicação governamental não é a única fonte de informação sobre os governos e suas dinâmicas, é certamente uma fonte única, pois é o discurso eleito para ser propagado por quem detém o poder de Estado.

Compreende-se assim que preservar a comunicação governamental e suas mídias institucionais é atender ao interesse público, pois o acesso às informações oficiais favorece a accountability, isto é, a compreensão, o acompanhamento, a físcalização e, quando necessário, a responsabilização dos atos oficiais por parte de cidadãos e de instâncias competentes. Especialmente no tema em tela, que envolve a vida e a morte dos cidadãos governados. E como a comunicação deste século é majoritariamente nascida digital, sendo nos sites oficiais onde se encontra a maior quantidade de produtos derivados dessa atividade, sua preservação passa pela manutenção das mídias digitais que os abrigam.

\section{Os sites analisados}

O levantamento que deu origem a este estudo, de caráter qualitativo, foi realizado por meio de pesquisa exploratória e documental nos endereços (URLs) previamente selecionados, a saber: o site do Ministério da Saúde, os sites dos 26 governos estaduais e o site do Distrito Federal (DF) criados exclusivamente para comunicar sobre a Covid-19. No total, foram 29 páginas analisadas ${ }^{5}$ (Quadro 1).

A partir do procedimento de navegação orientada, ${ }^{6}$ conduzida entre os dias 04 e 06 de agosto de 2020, foram relacionadas as seções, os temas e tipos de informações oferecidos em cada site. A partir daí, os dados foram agrupados, a fim de permitir uma visão de conjunto dos tipos de informações disponibilizadas.

\footnotetext{
${ }^{5} \mathrm{O}$ governo do Tocantins possui dois endereços relacionados à doença.

6 Tipo de navegação padronizada para pesquisa e coleta de dados em diferentes websites, a partir da criação e adoção de roteiro predefinido.
} 
Quadro 1 - Sites governamentais selecionados para análise

\begin{tabular}{|l|l|}
\hline \multicolumn{1}{|c|}{ Instância governamental } & \multicolumn{1}{c|}{ URL do website } \\
\hline Ministério da Saúde & 1. www.saude.gov.br/coronavirus \\
\hline Governo do Estado do Acre & 2. http://covid19.ac.gov.br \\
\hline Governo do Estado de Alagoas & 3. www.alagoascontraocoronavirus.al.gov.br \\
\hline Governo do Estado do Amapá & 4. https://corona.portal.ap.gov.br \\
\hline Governo do Estado do Amazonas & 5. www.coronavirus.amazonas.am.gov.br \\
\hline Governo do Estado da Bahia & 6. www.transparencia.ba.gov.br/CompraCovid19 \\
\hline Governo do Estado do Ceará & 7. www.coronavirus.ceara.gov.br \\
\hline Governo do Distrito Federal & 8. www.coronavirus.df.gov.br \\
\hline Governo do Estado do Espírito Santo & 9. https://coronavirus.es.gov.br \\
\hline Governo do Estado de Goiás & 10. www.saude.go.gov.br/coronavirus \\
\hline Governo do Estado do Maranhão & 11. www.corona.ma.gov.br \\
\hline Governo do Estado do Mato Grosso & 12. www.noticias.mt.gov.br \\
\hline $\begin{array}{l}\text { Governo do Estado do Mato Grosso do } \\
\text { Sul }\end{array}$ & 13. www.coronavirus.ms.gov.br \\
\hline Governo do Estado de Minas Gerais & 14. www.transparencia.mg.gov.br/covid-19 \\
\hline Governo do Estado do Pará & 15. www.covid-19.pa.gov.br \\
\hline Governo do Estado da Paraíba & 16. https://paraiba.pb.gov.br/diretas/saude/coronavirus \\
\hline Governo do Estado do Paraná & 17. www.coronavirus.pr.gov.br \\
\hline Governo do Estado de Pernambuco & 18. www.pecontracoronavirus.pe.gov.br \\
\hline Governo do Estado do Piaú & 19. http://coronavirus.pi.gov.br \\
\hline Governo do Estado do Rio de Janeiro & 20. https://coronavirus.rj.gov.br \\
\hline $\begin{array}{l}\text { Governo do Estado do Rio Grande do } \\
\text { Norte }\end{array}$ & 21. https://portalcovid19.saude.rn.gov.br \\
\hline $\begin{array}{l}\text { Governo do Estado do Rio Grande do } \\
\text { Sul }\end{array}$ & 22. https://coronavirus.rs.gov.br/inicial \\
\hline Governo do Estado de Rondônia & 23. www.rondonia.ro.gov.br/covid-19 \\
\hline Governo do Estado de Roraima & 24. https://roraimacontraocorona.rr.gov.br \\
\hline Governo do Estado de Santa Catarina & 25. www.coronavirus.sc.gov.br \\
\hline Governo do Estado de São Paulo & 26. www.saopaulo.sp.gov.br/coronavirus \\
\hline Governo do Estado de Sergipe & 27. https://todoscontraocorona.net.br \\
\hline Governo do Estado de Tocantins & $\begin{array}{l}\text { 28. www.coronavirus.to.gov.br } \\
\text { 29. http://integra.saude.to.gov.br/covid19 }\end{array}$ \\
\hline
\end{tabular}

Fonte: Desenvolvido pela autora.

Em etapa subsequente, as 29 URLs foram capturadas utilizando o software Conifer/Web Recorder, ferramenta de arquivamento da web que gera uma cópia das páginas e possibilita sua reprodução em qualquer tempo, independente de sofrer modificações ou de ser retirada do ar. A coleção, intitulada Sites oficiais Covid-19 Brasil, está disponibilizada por esta autora para acesso público. ${ }^{7}$

7 Disponível em: https://conifer.rhizome.org/anajaves/covid-19gov-estaduais/list/sites-oficiais-covid-19-brasil. Acesso em: 29 set. 2020. 
Pelas suas similaridades, primeiro serão apresentados os resultados do levantamento realizado nos sites dos governos estaduais e do DF. Os resultados foram agrupados em oito temas, definidos a partir do reconhecimento de padrões verificados nesse conjunto de sites, a saber: A doença; Evolução; Resposta do sistema de saúde; Orientações aos profissionais de saúde; Legislação; Transparência pública; Retomada econômica e Comunicação. O levantamento, não exaustivo, priorizou o agrupamento por tipos de informações disponíveis, a fim de avaliar a importância do acervo sobre a doença que essas mídias constituem.

Em seguida, serão indicados, separadamente, os conteúdos referentes ao site criado pelo Ministério da Saúde sobre a Covid-19. Ao final, a comunicação adotada sobre a doença no âmbito do Governo Federal é contextualizada, apontando em que medida ela interfere na política de preservação e de acesso a informações oficiais.

\section{O que os sites oficiais documentam sobre a Covid-19 no país}

Aproximadamente um mês após a confirmação do primeiro caso de Covid-19 no Brasil, diversas instâncias governamentais - desde o Governo Federal, por meio do Ministério da Saúde, até governos estaduais e prefeituras - colocaram no ar sites destinados a comunicar exclusivamente sobre a nova doença, de modo a facilitar o acesso da população, de pesquisadores e da imprensa a informações e indicadores oficiais.

De acordo com levantamento realizado no início do mês de abril de 2020 pelo Observatório da Comunicação Pública (OBCOMP), “48\% dos estados e 27\% das capitais criaram hotsites próprios para divulgar informações sobre o novo coronavírus; $11 \%$ dos governos estaduais e 19\% dos municipais criaram páginas específicas no site oficial" (GOVERNOS..., 2020). Em setembro de 2020, todos os governos estaduais possuíam sites dedicados exclusivamente a informar sobre a Covid-19 (Quadro 1).

Dentre os sites criados, os mais completos são os do Governo Federal e dos governos estaduais, tanto pela abrangência geográfica quanto pela variedade temática. Além de números oficiais, de informações técnicas e de orientações sanitárias, esses sites armazenam a comunicação governamental realizada sobre a doença, permitindo reconstituir, pela análise das notícias, discursos, entrevistas, vídeos, fotos, campanhas publicitárias e outras peças de comunicação, de que maneira as autoridades brasileiras trataram e se posicionaram sobre o 
tema. Devido à estrutura e à abrangência de dados, os sites permitem traçar um panorama detalhado da evolução da doença no país, o que motivou a tomá-los como corpus empírico deste artigo. A seguir, agrupados por temas, estão os principais tipos de informações encontrados nos sites dos governos estaduais e do DF.

A doença: informações sobre o novo coronavírus, os principais sintomas da doença (Covid-19) causada pela sua contaminação e as formas de evitar o contágio estão presentes em todos os websites analisados. Destinados à população em geral, que necessitava de orientações claras e confiáveis por parte das autoridades governamentais e de saúde, esses conteúdos são apresentados, em sua maioria, na forma de texto, infográficos, cartilhas digitais e vídeos. Além disso, há informações sobre tipos de tratamento, quem deve procurar atendimento médico, quando e onde se localiza o posto de saúde, Unidade de Pronto-Atendimento (UPA) ou hospital mais próximo.

Cabe ressaltar que, em razão de se tratar de uma nova enfermidade, essas informações foram frequentemente atualizadas, na medida em que as autoridades sanitárias adotavam novos protocolos. A necessidade de uso de máscara ou o momento de procurar atendimento médico são alguns exemplos de orientações que foram modificadas desde março de 2020. Em virtude dessa aprendizagem e das mudanças, muitos sites passaram a disponibilizar seções de "Perguntas Frequentes" ou "Tira-dúvidas".

Evolução: os números que permitem observar o crescimento da doença no país, isto é, o total de pessoas contaminadas, de pacientes recuperados e o número de óbitos foram os dados priorizados nos portais criados para informar sobre a Covid-19. Todos os sites analisados apresentam essas informações em destaque na página inicial, em números, tabelas e gráficos. Também é possível filtrar os dados por gênero, raça e idade, além de segmentar por municípios e/ou regiões. Dados da incidência da doença na população indígena e na população carcerária também são disponibilizados.

Resposta do sistema de saúde: os números de leitos de baixa, média e de alta complexidade (UTIs), incluindo os que foram criados após a pandemia, são atualizados de acordo com sua disponibilidade e ocupação. Aliás, esses dados, ao lado do número de casos confirmados e de mortes decorrentes da doença, foram e seguem sendo uma das principais 
informações demandadas e divulgadas diariamente pela imprensa de referência como indicador da evolução da pandemia em território nacional.

No que tange às respostas do sistema público de saúde, os governos estaduais também disponibilizam informações sobre a construção de hospitais de campanha ou de outros tipos de estruturas temporárias para atendimento de pacientes suspeitos ou confirmados, o número e os tipos de testes efetuados, bem como a oferta de serviços de telemedicina.

Orientações aos profissionais de saúde: na linha de frente do atendimento de saúde, médicos, enfermeiros, técnicos, auxiliares de enfermagem e fisioterapeutas também precisaram ser continuamente informados sobre a nova doença, formas de contaminação, sintomas e protocolos de atendimento. Em resposta, muitos sites criaram seções específicas para agrupar as informações voltadas a esse público, tais como boletins epidemiológicos, notas técnicas e instruções normativas, protocolos e fluxogramas de atendimento, planos de contingência, pesquisas e artigos científicos.

Legislação: decretos, leis, atos normativos e portarias, adotados em razão da pandemia ou já existentes, mas cujos regramentos deveriam ser observados pelos gestores públicos, foram disponibilizados para consulta. Os temas desses dispositivos legais vão desde a adoção de situação de emergência ou de calamidade pública nos estados a regulamentações para adquirir produtos e serviços destinados ao enfrentamento da pandemia; autorização/proibição de funcionamento de atividades industriais, comerciais e serviços; autorização/proibição de deslocamentos ou de aglomeração de pessoas; fechamento/abertura de espaços públicos; suspensão de aulas na rede pública e privada de ensino; uso obrigatório de máscaras em ambientes públicos e/ou privados etc.

Transparência pública: a prestação de contas online sobre receitas e despesas da administração pública é determinada pela Lei Complementar 131, de 2009, também conhecida como Lei da Transparência. Todos os entes da Federação - União, Estados, Distrito Federal e Municípios - devem disponibilizar em tempo real informações pormenorizadas sobre sua execução orçamentária e financeira. Com portais de transparência já em funcionamento, ficou mais simples atender à demanda crescente por informações sobre os investimentos feitos especificamente para conter a pandemia. 
Os sites criados pelos governos estaduais passaram a informar sobre os recursos aplicados no combate à doença, especialmente após o surgimento de denúncias de mau uso de recursos públicos, desvios de verbas e enriquecimento ilícito de gestores. É possível acessar informações sobre contratos e compras emergenciais, empenhos e pagamentos, aquisição de insumos, de equipamentos e de EPIs, convênios firmados, chamadas públicas e lançamento de editais. Além disso, há informações sobre doações (recebidas e encaminhadas), distribuição de testes e de EPIs por município e número de pedidos recebidos via Lei de Acesso à Informação e de respostas encaminhadas.

Retomada econômica: informações sobre a retomada das atividades econômicas também mereceram seção específica, em consequência dos impactos gerados pela sua suspensão a partir do recrudescimento da doença. Dessa forma, documentos como classificação das atividades como essenciais ou não-essenciais, critérios para autorização ou proibição de funcionamento, calendários de liberação por tipos de atividades, criação de linhas de créditos e planos de fomento à criação de emprego ou de ajuda aos trabalhadores desempregados estão publicadas nos sites governamentais.

Comunicação: a demanda por materiais de comunicação sobre a Covid-19 surgiu antes da confirmação do primeiro caso no país, pela necessidade de informar sobre a nova doença e o que se sabia sobre formas de contaminação, sintomas e prevenção. Os conteúdos produzidos e publicados pelos sites oficiais demonstram como o setor se adequou rapidamente ao cenário de uma população isolada em casa, ávida por informações confiáveis e que era, ao mesmo tempo, exposta a toda sorte de informações falsas, deturpadas ou associadas a teorias da conspiração. Assim, além de notícias, entrevistas e avisos de pauta, foram produzidas cartilhas, posts para redes sociais, campanhas publicitárias e conteúdos voltados a desmentir fake news. Canais de denúncia, seções de checagem e de contrainformação também compõem os esforços de comunicação no combate a notícias falsas, além do pedido de engajamento para que a população seja propagadora de informações confiáveis. Para isso, esses sites ofertam materiais gráficos para baixar e postar em mídias sociais.

As transmissões ao vivo com a participação de autoridades (conhecidas simplesmente como lives) chegaram a ocorrer diariamente no pico do número de contaminações e de mortes em alguns estados, e foram realizadas por governadores, secretários de saúde e outras 
autoridades envolvidas no enfrentamento da doença. Os registros audiovisuais dessas transmissões seguem disponíveis na maioria dos sites.

\section{O site do Ministério da Saúde e a comunicação do Governo Federal}

Maior instância governamental na área da saúde no país, o Ministério da Saúde (MS) colocou em prática, logo no início do mês de março, uma estratégia que envolveu a criação de novos canais digitais de comunicação entre o órgão, a população, jornalistas, cientistas e profissionais de saúde.

Em março de 2020, o MS lançou um aplicativo para smartphones, o Coronavírus-SUS, contendo informações sobre os sintomas da doença, como se prevenir, o que fazer em caso de suspeita e de infecção, entre outras orientações. No mesmo mês, também foi lançado um canal oficial no WhatsApp, em que um robô de atendimento automático recebe perguntas e fornece orientações. O site intitulado Painel Coronavírus (www.covid.saude.gov.br), com dados do Sistema Único de Saúde-SUS, foi criado para atualizar diariamente os principais números relativos à doença. Todas essas informações foram posteriormente consolidadas em um único endereço: www.coronavirus.saude.gov.br. Esse site, escolhido para compor o corpus desta pesquisa, é dividido em oito seções, cujos títulos e conteúdos, listados no Quadro 2, consolidam os itens disponíveis a partir da página principal. 
Quadro 2 - Conteúdos do site www.coronavirus.saude.gov.br

\begin{tabular}{|c|c|}
\hline SEÇÃO & CONTEÚDO \\
\hline O que você precisa saber & $\begin{array}{l}\text { - O que é Covid-19 } \\
\text { - Quais são os sintomas } \\
\text { - Como é transmitido } \\
\text { - Diagnóstico } \\
\text { - Se eu ficar doente } \\
\text { - Serviço de saúde } \\
\text { - Fake news } \\
\text { - Perguntas e respostas } \\
\text { - Painel Covid-19 } \\
\text { - App Coronavírus } \\
\end{array}$ \\
\hline Transparência & $\begin{array}{l}\text { - Portarias publicadas sobre Covid-19 } \\
\text { - Painel de leitos e insumos } \\
\text { - Gastos com Covid-19 } \\
\text { - Resposta brasileira à emergência }\end{array}$ \\
\hline Profissional e gestor & $\begin{array}{l}\text { - Boletins epidemiológicos } \\
\text { - Manejo clínico e tratamento } \\
\text { - Medidas não farmacológicas } \\
\text { - Definição de caso e notificação } \\
\text { - EPI } \\
\text { - Capacitação } \\
\text { - Cadastro de profissionais } \\
\text { - Saúde indígena } \\
\text { - Diagnóstico clínico e laboratorial } \\
\text { - Saúde e segurança do trabalhador (EPI) }\end{array}$ \\
\hline Publicações & $\begin{array}{l}\text { - Protocolos } \\
\text { - Publicações técnicas } \\
\text { - Revista do SUS }\end{array}$ \\
\hline Evidências científicas & $\begin{array}{l}\text { - Informe diário de evidências } \\
\text { - Diretrizes para o diagnóstico e tratamento da } \\
\text { Covid-19 } \\
\text { - Síntese de evidências } \\
\text { - Notas técnicas }\end{array}$ \\
\hline Pesquisa e Inovação & $\begin{array}{l}\text { - Chamadas públicas } \\
\text { - Pesquisas em andamento }\end{array}$ \\
\hline Assistência Farmacêutica & $\begin{array}{l}\text { - Notas técnicas } \\
\text { - Relação de medicamentos essenciais para manejo } \\
\text { de coronavírus } \\
\text { - Distribuição de medicamentos }\end{array}$ \\
\hline Últimas notícias & - Notícias do MS ligadas à Covid-19 \\
\hline
\end{tabular}

Fonte: Desenvolvido pela autora.

Apesar dos novos canais, e de todo o conteúdo disponibilizado no site oficial, conforme detalhado no Quadro 2, a estratégia de comunicação adotada pelo Ministério da Saúde foi controversa em muitos momentos. Para abordá-la, é preciso que se faça referência aos embates 
travados entre o presidente da República, Jair Bolsonaro, os governadores dos estados brasileiros e os ministros que ocuparam a pasta da Saúde de março até setembro de $2020 .{ }^{8}$ As divergências públicas entre o presidente, ministros e governadores no entendimento de como a nova doença deveria ser enfrentada se refletiram nas políticas de comunicação governamental e na falta de transparência na oferta de dados e de informações à sociedade.

Bolsonaro considera que a Covid-19 foi superdimensionada em outros países e que o mesmo não deveria se repetir no Brasil. Em diversas ocasiões, conforme levantamento publicado no Jornal do Commercio (ALBUQUERQUE, 2020, não paginado), o presidente minimizou a gravidade da situação, tratando a doença como "histeria" (17/03/2020), "gripezinha" (20/03/2020) e "resfriadinho" (24/03/2020), além de ter defendido o uso de um medicamento ainda sem eficácia comprovada, a cloroquina, e de ter desrespeitado as regras de distanciamento físico e de uso de máscara em locais públicos, adotadas em quase todos os estados brasileiros. Para Bolsonaro, o Ministério da Saúde não deveria endossar as recomendações da maioria dos governos estaduais de isolamento e de uso da máscara, defendendo ainda que o Ministério recomendasse o tratamento da doença com cloroquina. $\mathrm{Na}$ visão do presidente, os governadores estariam cometendo "um crime" (25/03/2020) ao seguir as orientações preconizadas pela Organização Mundial da Saúde (OMS). Para Bolsonaro (27/03/2020), "as consequências, depois dessas medidas equivocadas, vão ser muito mais danosas do que o próprio vírus" (ALBUQUERQUE, 2020, não paginado).

Um dos reflexos desses embates foi a troca de dois ministros da Saúde no momento em que o crescimento do número de casos e de mortes já indicava que a crise sanitária seria de grandes proporções no país. O outro foi a mudança na política de divulgação dos dados oficiais sobre a doença, após a escolha de um ministro da Saúde mais alinhado ao presidente.

No dia 5 de junho de 2020, o Ministério da Saúde passou a atrasar a divulgação dos dados oficiais que, até então, era feita em coletivas diárias ao final da tarde. No dia seguinte, 6 de junho de 2020, o site oficial do MS ficou fora do ar por algumas horas e, ao retornar, deixou de exibir os números consolidados sobre a doença que estavam disponíveis até então. O portal

\footnotetext{
${ }^{8}$ Luiz Henrique Mandetta assumiu o cargo no início do governo, em 01/01/2019, permanecendo até 16/04/2020; Nelson Teich ficou no cargo por menos de um mês, entre 17/04/2020 e 15/05/2020; e Eduardo Pazuello, que assumiu de forma interina no dia 02/06/2020, após a pasta passar duas semanas sem titular, foi efetivado no cargo em 17/09/2020 (MINISTÉRIO DA SAÚDE, 2020).
} 
passou a exibir apenas os números relativos às últimas 24 horas e deixou de informar o número total de pessoas infectadas pelo novo vírus, o acumulado de óbitos, as tabelas com a curva de evolução da doença desde o primeiro caso e os gráficos sobre infecções e mortes por Estado.

Pelo Facebook, o presidente da República confirmou: “o Ministério da Saúde adequou a divulgação dos dados sobre casos e mortes relacionados ao covid-19" (BOLSONARO, 2020). No dia anterior, no entanto, em fala aos jornalistas, havia abordado a mudança de outra forma: “acabou matéria do Jornal Nacional” (GARCIA, 2020, não paginado), em referência ao telejornal noturno da Rede Globo que, assim como os demais veículos de imprensa, foi prejudicado com o atraso na divulgação das informações.

Em resposta, dois dias após a decisão de retirar informações e atrasar a divulgação dos dados consolidados, grandes veículos de comunicação decidiram criar o que chamaram de “Consórcio de Imprensa”. Formado por G1, O Globo, Extra, O Estado de S. Paulo, Folha de S. Paulo e $U O L$, os jornalistas dessas empresas passaram a trabalhar de forma colaborativa e a buscar informações sobre a pandemia diretamente nas secretarias da Saúde dos 26 estados e do Distrito Federal (VEÍCULOS..., 2020, não paginado). O Consórcio segue ativo e divulgando diariamente os dados da pandemia, por vezes divergentes dos dados oficiais divulgados pelo Ministério da Saúde.

O site oficial do Ministério da Saúde permanece no ar e com inúmeros conteúdos disponíveis, inclusive atualização dos números relativos à evolução da doença e medidas adotadas para seu enfrentamento. No entanto, permanece a incerteza quanto à integridade dos dados disponibilizados, sua veracidade e garantia de preservação desses conteúdos para acesso futuro.

\section{Considerações finais}

Este artigo apresentou os tipos de conteúdos disponibilizadas nos sites oficiais dos governos estaduais, do Distrito Federal e do Ministério da Saúde criados para informar sobre a pandemia do novo coronavírus, com o objetivo de discutir a importância de uma política de preservação dessas mídias institucionais, que permitem constituir a memória da Covid-19 no Brasil. Além de informações e de dados brutos que favorecem o trabalho de jornalistas, de pesquisadores e da comunidade científica, esses sites são também repositórios da comunicação 
realizada no período, possibilitando acesso aos discursos oficiais, entrevistas, notícias e demais conteúdos informativos e publicitários oferecidos à população sobre o tema. Um acervo valioso, mas que não possui garantia de preservação.

A Covid-19 é uma doença recente e a documentação dos erros e acertos no seu enfrentamento compõe uma importante curva de aprendizagem para nações de todo o mundo. Graells (2020), em entrevista sobre preservação digital e sistemas de saúde, afirma:

\begin{abstract}
Esta pandemia fez com que distintos coletivos fizessem um chamamento a favor de que a informação científica, nesse caso, as descobertas sobre a natureza da Covid-19 e seus possíveis remédios e soluções, esteja livre e acessível para todos. [...] E nesse ponto, a preservação digital vem assegurar esse acervo comum que estamos criando entre todos, tanto do setor privado quanto do setor público. (GRAELLS, 2020, p. 726, tradução da autora). ${ }^{9}$
\end{abstract}

Ocorre que se o governo federal brasileiro não tem compromisso com a transparência ou a manutenção dos dados publicados em suas mídias oficiais, conforme abordado neste trabalho, e se há comprovadas práticas de retirada de conteúdos de sites oficiais também em outros níveis governamentais (LUZ; WEBER, 2018; LUZ, 2016), a memória administrativa, política, social e comunicacional do país está sob risco.

Cabe observar que iniciativas independentes de arquivamento da web ainda enfrentam desafios, tanto técnicos quanto de alcance, que não nos permitem contar unicamente com essa alternativa como garantia de acesso futuro aos conteúdos oficiais. Melo e Rockembach (2020), em recente estudo que verificou a qualidade do arquivamento web em quatro sites de órgãos governamentais brasileiros da área da saúde, atestaram que o desempenho dos websites não foi considerado de alta qualidade, bem como o acesso de robôs de captura (crawlers) não foi autorizado para algumas coletas no caso dos sites do Ministério da Saúde e da Anvisa. Os pesquisadores lembram que um dos principais desafios do arquivamento da web é justamente compreender que "websites podem não ser arquivados corretamente, em razão de problemas que surgem a partir do uso de diferentes tecnologias, padrões e práticas de implementação de páginas” (MELO; ROCKEMBACH, 2020, p. 531).

\footnotetext{
${ }^{9}$ No original: "Esta pandemia ha hecho que en distintos colectivos haya unos llamamientos a favor de que la remedios y soluciones, para que todo este tipo de información esté libre, y accesible para todos [...] Y en este punto, la preservación digital viene a afianzar este acervo común que estamos creando entre todos, tanto del sector privado como del sector público" (GRAELLS, 2020, p. 726).
} 
Por isso, a fim de que se possa ter assegurados os direitos à informação e à memória esperados nas democracias, e que os governos e autoridades estejam comprometidos com a transparência pública e com os processos de fiscalização e de accountability, é imprescindível acompanhar o destino que essas mídias institucionais recém-criadas terão. Sem garantia de preservação e de acesso aos seus conteúdos, a memória da Covid-19 no Brasil estará seriamente comprometida, assim como a aprendizagem resultante do enfrentamento da pandemia.

\section{Referências}

ALBUQUERQUE, Alice. Gripezinha, histórico de atleta e aglomerações: a cronologia de Bolsonaro até contrair o coronavírus. Jornal do Commercio, Recife, 7 jul. 2020. Disponível em: https://jc.ne10.uol.com.br/politica/2020/07/11953165-gripezinha--historico-de-atleta-eaglomeracoes--a-cronologia-de-bolsonaro-ate-contrair-o-coronavirus.html. Acesso em: 30 set. 2020 .

BOLSONARO, Jair (@ jairmessias.bolsonaro). Brasília, 06. Jun. 2020. Facebook: usuário Facebook. Disponível em:

https://www.facebook.com/jairmessias.bolsonaro/posts/1963078020507841/. Acesso em: 30 maio 2021.

FORMENTON, Danilo; GRACIOSO, Luciana de Souza. Preservação digital: desafios, requisitos, estratégias e produção científica. RDBCI: Revista Digital de Biblioteconomia e Ciência da Informação, Campinas, SP, v. 18, n. 00, p. e020012, 2020. DOI:

10.20396/rdbci.v18i0.8659259. Disponível em:

https://periodicos.sbu.unicamp.br/ojs/index.php/rdbci/article/view/8659259. Acesso em: 31 maio. 2021.

FREY, Klaus et al. O acesso à informação. In: SPECK, Bruno (org.). Caminhos da transparência: análise dos componentes de um sistema nacional de integridade. Campinas, SP: Editora Unicamp, 2002. p. 169-183.

GARCIA, Gustavo. 'Acabou matéria do Jornal Nacional', diz Bolsonaro sobre atrasos na divulgação de mortos por coronavírus. G1, 05 jun. 2020. Política. Disponível em: https://g1.globo.com/politica/noticia/2020/06/05/dados-do-coronavirus-bolsonaro-defendeexcluir-de-balanco-numero-de-mortos-de-dias-anteriores.ghtml. Acesso em: 30 maio 2020.

GOVERNOS brasileiros criam canais de comunicação sobre a Covid-19. Observatório da Comunicação Pública. 03 abr. 2020. Disponível em: www.ufrgs.br/obcomp/noticias/0/1777/governos-brasileiros-criam-canais-de-comunicacaosobre-a-covid-19/hotsite. Acesso em: 01 set. 2020.

GRAELLS, Miquel Térmens. La importancia de la preservación digital para los sistemas de salud (entrevista). [Entrevista cedida a] Miguel Angel Márdero Arellano e Andréa Gonçalves. 
Reciis - Revista eletrônica de Comunicação, Informação \& Inovação em Saúde, Rio de Janeiro, v. 14, n. 3, p. 724-733, jul./set. 2020. Disponível em:

https://doi.org/10.29397/reciis.v14i3.2159. Acesso em: 30 set. 2020.

HOWLETT, Michael. Government communication as a policy tool: a framework for analysis. Canadian Political Science Review, v. 3, n. 2, p. 23-37, 2009. Disponível em: https://ojs.unbc.ca/index.php/cpsr/article/view/134. Acesso em: 23 set. 2020.

LUZ, Ana Javes Andrade da. Comunicação pública e memória das cidades: a preservação dos sistemas de comunicação nos sites das capitais brasileiras. 2016. Dissertação (Mestrado em Comunicação e Informação) - Programa de Pós-Graduação em Comunicação e Informação, Universidade Federal do Rio Grande do Sul, Porto Alegre, 2016.

LUZ, Ana Javes Andrade da; WEBER, Maria Helena. Comunicação governamental e memória política. In: BENETTI, Marcia; BALDISSERA, Rudimar (org.). Pesquisa e perspectivas de comunicação e informação. Porto Alegre: Sulina, 2018. p. 15-37.

MELO, Jonas Ferrigolo; ROCKEMBACH, Moisés. Arquivabilidade de websites para preservação digital: estudo a partir da área da saúde. Reciis - Revista eletrônica de Comunicação, Informação \& Inovação em Saúde, Rio de Janeiro, v. 14, n. 3, p. 529-543, jul./set. 2020. Disponível em: https://doi.org/10.29397/reciis.v14i3.2116. Acesso em: 30 set. 2020 .

MINISTÉRIO DA SAÚDE. Disponível em: https://www.gov.br/saude. Acesso em: 30 maio 2021.

NTOULAS, Alexandros; CHO, Junghoo; OLSTON, Christopher. What's new on the web?: the evolution of the web from a search engine perspective. In: Proceedings of the 13th international conference on World Wide Web. ACM, 2004. p. 1-12.

PIMENTA, Marcelo Soares; CANABARRO, Diego Rafael. Apresentação: Democracia e capacidade estatal na era digital. In: PIMENTA, Marcelo Soares; CANABARRO, Diego Rafael (org.). Governança digital. Porto Alegre: UFRGS/CEGOV, 2014. p. 9-11.

ROCKEMBACH, Moisés. Arquivamento da web: estudos de caso internacionais e o caso brasileiro. RDBCI: Revista Digital Biblioteconomia e Ciência da Informação, Campinas, SP, v. 16, n. 1, p. 7-24, 2018a. Disponível em: https://doi.org/10.20396/rdbci.v16i1.8648747. Acesso em: 13 nov. 2019.

ROCKEMBACH, Moisés. A web retrospectiva como campo de pesquisa: arquivamento da web e preservação digital. In: BENETTI, Marcia; BALDISSERA, Rudimar (org.). Pesquisa e perspectivas de comunicação e informação. Porto Alegre: Sulina, 2018b. p. 240-256. 
UNESCO-Organização das Nações Unidas para a Educação, a Ciência e a Cultura. Carta sobre la preservación del patrimonio digital. 15 oct. 2003. Disponível em:

http://bit.ly/UNESCO_patrimoniodigital. Acesso em: 23 set. 2020.

VEÍCULOS de comunicação formam parceria para dar transparência a dados de Covid-19. G1, 08 jun. 2020. Política. Disponível em:

https://g1.globo.com/politica/noticia/2020/06/08/veiculos-de-comunicacao-formam-parceriapara-dar-transparencia-a-dados-de-covid-19.ghtml. Acesso em: 30 set. 2020.

WEBER, Maria Helena. Nas redes de comunicação pública, as disputas possíveis de poder e visibilidade. In: WEBER, Maria. Helena; COELHO, Maria. P.; LOCATELLI, Carlos (org.). Comunicação pública e política: pesquisa \& práticas. Florianópolis: Insular, 2017. v. 1, p. 23-56.

WORLD HEALTH ORGANIZATION. Archived: WHO Timeline - COVID-19. 27 Apr. 2020a. Disponível em: https://www.who.int/news/item/27-04-2020-who-timeline---covid-19. Acesso em: 30 maio 2021.

WORLD HEALTH ORGANIZATION. WHO Director-General's opening remarks at the media briefing on COVID-19 - 11 March 2020. 11 Mar. 2020b. Disponível em: https://www.who.int/director-general/speeches/detail/who-director-general-s-openingremarks-at-the-media-briefing-on-covid-19---11-march-2020. Acesso em: 30 maio 2021.

Submetido em: 01.10.2020.

Aprovado em: 09.11.2020. 